University of Warwick institutional repository

This paper is made available online in accordance with

publisher policies. Please scroll down to view the document

itself. Please refer to the repository record for this item and our

policy information available from the repository home page for further information.

To see the final version of this paper please visit the publisher's website. Access to the published version may require a subscription.

Author(s): Lucy M. HARTWRIGHT, Paul J. HUNTER, John A. WALSH

Article Title: A comparison of Olpidium isolates from a range of host plants using internal transcribed spacer sequence analysis and host range studies

Year of publication: 2009

Link to published version :

http://dx.doi.org/10.1016/j.mycres.2009.09.008

Publisher statement: None 


\section{A comparison of Olpidium isolates from a range of host plants using internal transcribed spacer sequence analysis and host range studies.}

Lucy M. HARTWRIGHT, Paul J. HUNTER and John A. WALSH*

Warwick HRI, University of Warwick, Wellesbourne, Warwick, CV35 9EF, UK.

*Corresponding author. $\quad$ Fax: +44 (0)2476 574500

Telephone: +44 (0)2476 575028

E-mail address: john.walsh@warwick.ac.uk

Running title: Olpidium brassicae host types

Keywords:

Fungus

Chytridiomycete

Virus vector

PCR

\section{ABSTRACT}

Olpidium brassicae is a ubiquitous obligate root-infecting fungal pathogen. It is an important vector of a wide range of plant viruses. Olpidium isolates that infected brassica plants did not infect lettuce plants and vice-versa. Host range tests, PCR amplification and sequencing of the internal transcribed spacer (ITS) and 5.8S regions of 25 Olpidium isolates from brassica, carrot, cucumber and lettuce originating from four continents revealed differences between isolates. Based on their ability to infect lettuce and brassicas and the differences between their ITS1, 5.8S and ITS2 regions they could be separated into a number of distinct groups. Comparisons with other 
published sequences revealed two distinct genetic groups of brassica-infecting isolates, two distinct groups of lettuce-infecting isolates, one of which contained a carrot-infecting isolate and a distinct group comprising a cucumber-infecting isolate and a melon-infecting isolate. The possibility of the isolates belonging to three distinct species is discussed.

\section{Introduction}

Olpidium brassicae, a Chytridiomycete fungus, is a soil-borne obligate parasite that infects plant roots. Resting spores can remain dormant in the soil and are still infective after 20 years (Campbell 1985), making eradication virtually impossible once the fungus is established. Control is also difficult because $O$. brassicae infects a range of weed species which can act as reservoirs. Olpidium species have been found to infect many different crop plants including cucumber, lettuce, carrot and brassicas such as broccoli and cabbage (Campbell \& Sim 1994). O. brassicae isolates collected from lettuce and brassica host species have been shown to be morphologically identical (Garrett \& Tomlinson 1967). O. brassicae is described as having stellate resting spores and small, spherical $(3 \mu \mathrm{m})$ zoospores (Campbell \& Sim 1994).

Olpidium spp. are economically important as fungal vectors of several plant viruses (Campbell 1996). For example, they have been shown to transmit Cucumber necrosis virus, Melon necrotic spot virus, Tobacco necrosis virus and Tobacco stunt virus (TStV) (Campbell 1996). O. brassicae transmits Mirafiori lettuce big-vein virus (MLBVV) the cause of lettuce big-vein disease (Lot et al. 2002) and Lettuce big-vein associated virus (formerly Lettuce big-vein virus; Kuwata et al. 1983; Huijberts et al. 1990) commonly found in plants with lettuce big-vein disease. Big-vein is a common 
and destructive disease affecting lettuce crops with typical symptoms of vein-banding accompanied by crinkling and distortion of leaves. These symptoms have a major economic impact as they can reduce the proportion of harvestable heads by preventing or delaying head formation and causing a decrease in head size (Ryder 1980; Walsh 1992).

Detection of O. brassicae in soil or in the roots of crops or weed species could help in the control of the important viruses transmitted by $O$. brassicae; testing plants and/or soil could allow the planting of susceptible crops into contaminated soil to be avoided. Previously, the internal transcribed spacer (ITS) regions, between the 18S, 5.8S and 28S genes, have been shown to be sufficiently variable to distinguish closely related fungal species (Cooke \& Duncan 1997). They also have the potential to distinguish between isolates of the same species from different host plants (Ward \& Adams 1998). Prior to our release of ITS sequence information on O. brassicae of worldwide provenance and from a number of host species (GenBank accession numbers AY373011, AY373013, AY373012, AY373015 and AY373014) in 2004, there was only information available on one isolate (Ward \& Adams 1998) originating from lettuce in the USA. Subsequently further sequences have been published (James et al. 2006; Sasaya \& Konganezawa 2006) on isolates from a range of hosts, but, with one exception, all were from Japan. This paper describes the genetic variation between the ITS regions of Olpidium isolates with different virus transmission specificities obtained from different host plants and different geographical regions and compares this with published data and also describes host plant specificities. 


\section{Materials and methods}

\section{Fungal isolates and propagation}

Olpidium isolates present in the roots of different host plants were collected over several years from many different locations. The geographical and host origins of each Olpidium isolate are summarised in Table 1.

Lettuce (Lactuca sativa) cultivar Little Gem, broccoli (Brassica oleracea) cultivar Marathon and carrot (Daucus carota) cultivar Autumn King seeds were sown in vermiculite. Seven days after sowing, seedlings were transferred into trays filled with nutrient solution (Walsh 1994). After a further seven days, seedlings were inoculated by placing dried Olpidium-infected roots into the nutrient solution, or by placing an infected live host plant into the tray of uninfected plants. Seedlings were maintained in the nutrient solution until four weeks after inoculation after which the roots were prepared for zoospore extraction.

Host range tests and microscopy

The Olpidium isolates used during this study were tested for their ability to infect different plant species other than their original host. Lettuce, broccoli, carrot and cucumber seedlings were grown in trays as described above and exposed to different Olpidium isolates by placing infected host plants into the trays. Four weeks after exposure to Olpidium, plant roots were examined for Olpidium infection under a light microscope. A minimum of five plants each of lettuce, broccoli, carrot and cucumber were tested with the respective Olpidium isolates on each occasion and tests were repeated up to four times. 
Zoospore production and DNA isolation

Plant roots were inspected under the microscope to verify infection with $O$. brassicae. If infection (i.e. presence of resting spores and/or zoosporangia) was observed in the roots, plants were removed from nutrient cultures and stored at $4^{\circ} \mathrm{C}$ for four days in plastic bags. The roots were then placed in distilled water containing $10 \mathrm{~g}^{-1}$ sucrose and 0.05 M glycine (Teakle \& Gold 1964), at $4^{\circ} \mathrm{C}$ for one hour for zoospore release. After removal of plants, the solution was filtered through two layers of soft muslin and one sheet of filter paper (Whatman, No. 4) to remove large debris and centrifuged at $400 \mathrm{~g}$ at $4{ }^{\circ} \mathrm{C}$ for 10 minutes. The supernatant was decanted and the pellet resuspended in sterile distilled water. The number of zoospores present in the pellet was quantified using a haemacytometer. Zoospores were lysed and genomic DNA was isolated using a plant DNA extraction kit (DNeasy, Qiagen, Crawley, UK).

PCR and sequencing of the ITS regions

PCR products were amplified following the conditions described by White et al. (1990) from genomic zoospore DNA using their primers NS7 (5'GAGGCAATAACAGGTCTGTGATGC-3’) and ITS4 (5’TCCTCCGCTTATTGATATGC-3’) which amplify a product of approximately $1 \mathrm{~kb}$ including both the ITS1 and ITS2 regions. At least two independent PCR amplifications were carried out on DNA from each Olpidium isolate. Amplification of DNA from most isolates produced a single band of approximately $1 \mathrm{~Kb}$. Single bands were then cut from agarose gels and the DNA was extracted using a gel 
extraction kit (Qiagen, Crawley, UK) and sequenced. The NS7 and ITS4 primers were used to sequence both strands of each PCR product. Additionally, amplification and sequence information were obtained with the primers ITS1 (5'TCCGTAGGTGAACCTGCGG-3'; White et al. 1990) and ITS6R (5'GCTTAAGTTCAGCGGGTAATCCTAC-3’) for isolates where either NS7 and/or ITS4 failed to produce product/sequence. The latter primer was designed based on the published sequence of $O$. brassicae (Ward \& Adams 1998). Sequencing was performed using BigDye dideoxy terminator chemistry (Applied Biosystems, USA) and an ABI 3100 automatic sequencing machine (Applied Biosystems, USA).

ITS1 and ITS2 sequence analysis

Similarities between the Olpidium sequences obtained and other sequences in the GenBank database were sought using BLASTN (Altschul et al. 1997). ITS sequences from Olpidium isolates GBR1, NLD4, ITA1, GBR7 and GBR10 (accession numbers AY373011, AY373013, AY373012, AY373015 and AY373014 respectively) have been deposited in the GenBank database (http://www.ncbi.nlm.nih.gov/Genbank/). Sequences were initially aligned using the program Seqman (DNAStar Inc., USA).

\section{Phylogenetic analysis}

The nucleotide sequences of the ITS regions of the $25 \mathrm{O}$. brassicae isolates sequenced (Table 1), Y12830 (Ward \& Adams 1998), AY997067 (James et al. 2006) and the 11 Japanese isolates (Sasaya \& Konganezawa 2006) were aligned using ClustalX (Thompson et al. 1997). Sequential analyses were then performed using the PHYLIP 
programs DNADIST, DNAPARS (Felsenstein 1995) and fastDNAML (Olsen et al. 1994). NJPlot (Perrière \& Gouy 1996) was used to visualise phylogenetic trees. The sequence of Rhizopus oryzae (GQ220706) was used as an out-group. Branch support was assessed by bootstrapping using 1000 random resamples. Full-length sequences of all the PCR products (comprising the entire ITS1-5.8S-ITS2 region and associated available 18S sequence) were compared to sequence databases using the megaBLAST facility at http://www.ncbi.nlm.nih.gov/blast (Zhang et al. 2000). The length of $18 \mathrm{~S}$ sequence available for different Olpidium isolates varied and hence was not compatible with the phylogenetic analysis. Consequently, only the ITS1-5.8S-ITS2 region (complete for all our isolates) was used for further comparisons.

\section{Results}

Sequence analysis of the ITS regions

PCR products of approximately $1 \mathrm{~kb}$ were obtained from the genomic DNA of each isolate using the primers NS7 and ITS4. These primers did not amplify a product from all isolates; in such instances NS7 and ITS6R were used. On occasions where zoospore numbers were low and/or not free of host material, NS7 and ITS4 amplified host plant DNA from lettuce, carrot and cucumber. These products were approximately $1 \mathrm{~kb}$ in size and sequence analysis revealed very high identity to respective host plant sequences.

The partial 18S sequences obtained with the NS7 and ITS4 primers were identical for all isolates and were not used in the analyses. Comparisons of the ITS and 5.8S RNA 
nucleotide sequences from all of the $O$. brassicae isolates infecting lettuce, brassicas, carrot and cucumber showed that some were identical. The sequences were identical for the four brassica-infecting isolates (GBR4, GBR5, GBR7 and GBR8), consequently GBR7 (AY373015) was used as representative of this group. The sequences of 16 lettuce isolates (AUS1, AUS2, BEL1, CHL1, DEU1, ESP1, ESP2, FRA5, GBR1, GBR2, JPN1, NLD1, NLD2, PRT1, PRT2 and USA2) and the carrot isolate (GBR3) were also identical to each other (GBR1 used as representative, AY373011). Two other lettuce isolates (ITA1 and NLD3; ITA1 used as representative, AY373012) had identical sequences to each other, but were different to all other lettuce isolates. In terms of the Olpidium isolates we studied, sequences of the NLD4 isolate (AY373013) from lettuce and GBR10 (AY373014) from cucumber were unique, however the latter was identical to that of a partial sequence of $O$. brassicae from the AFTOL study (James et al. 2006). The AFTOL O. brassicae was isolate SS218, T.D. James (personal communication) which originated from melon in France (Campbell \& Sim 1994). An alignment of the five different DNA sequences of the ITS1 and ITS2 regions and 5.8S gene is shown in Fig 1. The 5.8S sequences of our O. brassicae isolates was defined based on that published in the AFTOL study (James et al. 2006) and the ITS1 and ITS2 regions identified relative to the 5.8S sequence and the primers. The $5.8 \mathrm{~S}$ sequence was $155 \mathrm{bp}$ in size for all our isolates. The ITS1 region was 132 bp for all isolates except the brassica isolates (102 bp) and the lettuce isolate NLD4 (134bp). The ITS2 region was 268 bp for most isolates with the exception of the brassica isolates (266 bp), NLD4 (269 bp) and ITA1 (269 bp).

A database search was carried out with the ITS1, 5.8S and ITS2 sequences of the GBR1 isolate of $O$. brassicae, separately and as a single contiguous sequence using 
BLAST. This revealed that the $O$. brassicae isolates had very high identity to the previously published O. brassicae sequence (Y12830) (Ward \& Adams 1998). Our lettuce sequences showed one nucleotide difference to that of Ward and Adams (1998) and high levels of similarity with the published sequences of other Olpidium species (Sasaya \& Koganezawa 2006; James et al. 2006), which are included in our phylogenetic analysis. There were different lengths of $18 \mathrm{~S}$ sequence available for the isolates, however, BLAST searches using megaBLAST with the maximum available 18S-ITS1-5.8S-ITS2 region for all our isolates found no significant hits for anything other than to Olpidium spp. or unidentified Olpidiaceae. The closest matches to organisms other than Olpidiaceae were to the Glomeromycete, Acaulospora trappei (56-57\%), the Zygomycete, Mortierella alpina (22-34\%), Cercomonadida (protist) (27-37\%) and the Basidiomycete, Bullera pseudohuianensis (24-27\%). Over 156 bp of the 5.8S gene, a Trichosporon sp. (Basidiomycete) showed 96\% identity. Comparison of $5.8 \mathrm{~S}$ sequences of the isolates in our study with those for the next nearest neighbours (Zygomycota) and representative isolates from all the Chytridiomycete groups identified in the AFTOL study (AFTOL IDs 301, 28, 137 [Zygomycota] and 19, 300, 20, 638 and 297 [Chytridiomycota]; ITS sequences not used in AFTOL study) (James et al. 2006), indicated that all the isolates in our study were more closely associated with the O. brassicae isolate (AFTOL ID 633) than any of these fungal species. The AFTOL study (James et al. 2006) based on six gene regions indicated that Olpidium isolates are more closely related to a member of the Zygomycota (Basidiobolus ranarum) than the non-monophyletic Chytridiomycota.

Phylogenetic analysis 
The phylogenetic tree of our Olpidium sequences combined with other available sequences (Fig. 2) showed that the $O$. brassicae isolates comprised five significantly different branches. The brassica-infecting isolates were significantly different to all the other isolates and consisted of two distinct branches; one branch comprised Japanese brassica isolates (Sasaya \& Koganezawa 2006) and the other, all our UK brassica isolates. The other three branches consisted of one comprising an onion isolate (WOms-3, isolated from Welsh onion in Japan; Sasaya \& Koganezawa 2006), our carrot isolate (GBR3) and most of our lettuce isolates, a second comprising four Japanese isolates (CH-1 and TAK1 from tobacco and KZ-1 and HY-1 from lettuce; Sasaya \& Koganezawa 2006) and our other lettuce isolates (NLD3 and NLD4 from Holland and ITA1 from Italy) and the final branch comprised our cucumber isolate (GBR10) and the melon isolate from the AFTOL study (James et al. 2006).

Isolate host specificity

The host ranges of the 25 Olpidium isolates tested are shown in Table 2. All of the isolates from brassica hosts did not infect lettuce or carrot and the one isolate tested (GBR4), didn't infect cucumber. They did infect the broccoli used in the host range tests. All lettuce isolates only infected lettuce and not carrot or broccoli. The one lettuce isolate tested (GBR1), didn't infect cucumber. The isolate GBR3, from carrot, infected lettuce as well as carrot but it did not infect broccoli or cucumber. GBR10, a cucumber isolate did not infect lettuce, carrot or broccoli. 


\section{Discussion}

Molecular and host range comparisons between isolates of $O$. brassicae originating from four different host plants (lettuce, brassica, cucumber and carrot) and four continents (America, Asia, Europe and Oceania) have been made. Morphologically, the zoospores and resting spores from lettuce-, brassica-, cucumber- and carrotinfecting $O$. brassicae isolates were indistinguishable, however, the analysis of the ITS regions revealed consistent and significant differences between some host types. Previously, host range and morphology have been used to determine speciation of Olpidium (i.e. O. brassicae and O. bornovanus; Lange \& Insunza 1977). The cucumber-infecting isolate of our study was previously classified as Olpidium radicale by Tomlinson and Thomas (1986). They observed elongated zoospores and the honeycomb-like endospore wall structure as described by Lange and Insunza (1977). O. radicale was subsequently renamed as O. bornovanus by Campbell and Sim (1994). During our study, we observed that this isolate, which definitely infected cucumber, had spherical zoospores and stellate resting spores identical to those of the O. brassicae isolates from lettuce, brassica and carrot. The ITS-5.8S analysis also showed that the cucumber-infecting and the AFTOL 633 melon O. brassicae isolates were identical and phylogenetically distinct from the lettuce- and brassica-infecting isolates of O. brassicae. Sasaya and Koganezawa (2006) reported that the ITS region of $O$. bornovanus was $1137 \mathrm{bp}$, almost twice the size of those of the crucifer and other non-crucifer infecting Olpidium isolates, further supporting the identity of our cucumber-infecting isolate as $O$. brassicae rather than $O$. bornovanus. Additionally, electron micrographs taken of the zoospores of the cucumber isolate during the 1980s showed spherical, not elongated zoospores. Consequently we conclude that the 
cucumber isolate of Tomlinson and Thomas (1986) is O. brassicae and not $O$. bornovanus.

Our sequence analysis of the ITS regions of 25 isolates of $O$. brassicae has provided useful additional information to that published previously (Ward \& Adams, 1998; Sasaya \& Koganezawa, 2006; James et al. 2006). Our analyses along with the results from our host range experiments have confirmed that lettuce-infecting isolates are distinct from brassica-infecting isolates and the two groups should be classified as two distinct species. Sahtiyanci (1962) divided crucifer-infecting and lettuce-infecting Olpidium isolates in to two distinct species, Pleotrachelus brassicae and P. virulentus respectively. The genus name given by Sahtiyanci has not been adopted, although Sasaya and Koganezawa (2006) used the specific names (O. brassicae and $O$. virulentus). As the original species $O$. brassicae was named after the host plant, perhaps it might be more appropriate to refer to lettuce-infecting isolates as $O$. compositae rather than O. virulentus; it is known that isolates of Olpidium from lettuce are able to infect other members of the family Compositae. However, $O$. compositae might not be the ideal name, as we have a carrot isolate that has an identical ITS sequence to that of Olpidium isolates originating from lettuce and that will infect lettuce and yet lettuce isolates we have tested did not infect carrot. Also, the Japanese isolate WOms-3 (Sasaya \& Koganezawa, 2006) that grouped with our lettuce isolates was isolated from onion. As the Olpidium isolate (GBR10) from cucumber formed a branch separate from lettuce- and brassica-infecting isolates, based on the criteria for considering lettuce and brassica isolates as different species, it too could be considered to be a different species and $O$. cucurbitaceae could be 
considered as a candidate name. This is supported by the fact the AFTOL $O$. brassicae isolate that had an identical sequence, also originated in a cucurbit (melon).

Most (16) of our lettuce-infecting O. brassicae isolates were identical in terms of their ITS and 5.8S RNA nucleotide sequences despite originating from widely different geographical regions. Of our three lettuce isolates that differed, two were identical to each other and the third had a unique sequence. The ITS and 5.8S sequences of the four brassica isolates were identical. ITS sequences appear to be conserved to some extent within host-specific groups. A reason for this conservation might be because O. brassicae has such a specialised obligately parasitic life-cycle and host ranges may not overlap significantly. The significant differences between the sequences of our brassica isolates and the Japanese brassica isolates and between most of our lettuce isolates and most of the Japanese lettuce and tobacco isolates suggests early geographic spread and isolation. The presence of one Japanese lettuce isolate in our major lettuce group and clustering of our Dutch and Italian lettuce isolates with the Japanese lettuce and tobacco isolates indicates that there has also been more recent geographic spread.

The ITS regions of some fungi have been shown to be highly variable. For example, Colletotrichum lindemuthianum (Balardin et al. 1999) and Fusarium oxysporum (Duggal et al. 1997) have highly variable ITS regions within species. However, other fungi have very conserved ITS regions within species such as Phytophthora pseudosyringae (Jung et al. 2003) and Coniothyrium minitans (Muthumeenakshi et al. 2001). The differences in ITS sequences between isolates specific to different host plants indicated that molecular tests capable of discriminating Olpidium isolates with 
different host ranges and virus-vectoring specificities could be devised to allow testing of field soils and determination of risk of infection and hence transmission of important Olpidium-transmitted viruses. A multiplex PCR assay for the detection and discrimination of $O$. brassicae, $O$. virulentus and $O$. bornovanus has been developed (Herrera-Vásquez et al. 2009). The test does not appear to be currently capable of discriminating between lettuce- and cucurbit-infecting isolates of Olpidium. Our GBR10 sequence, the identical AFTOL sequence and phylogenetic analysis suggests it might be possible to extend the assay to discriminate between these host specialised groups that have different virus vectoring abilities, providing ITS sequences of other cucurbit-infecting Olpidium isolates are different to those of lettuce-infecting isolates. Although there is a difference in host plant specificity between the Olpidium isolate from carrot and all the lettuce-infecting isolates in our study (none of the lettuce isolates infected carrot, whereas the carrot isolate infected lettuce and carrot) their ITS1-5.8S-ITS2 sequences were identical. In this instance and any other similar situations, other regions of the Olpidium genome will need sequencing in order to develop molecular tests capable of discriminating between the host specific groups. The only sequences currently available from other regions of the Olpidium genome are the $28 \mathrm{~S}$ elongation factor 1-alpha and two RNA polymerase II subunits for a single isolate (James et al. 2006).

With the limited information on the virus vectoring specificities of the Olpidium isolates we sequenced, it is dangerous to speculate on correlations with ITS sequences. Sasaya and Koganezawa (2006) showed that non-crucifer infecting Olpidium isolates transmitted MLBVV and TStV, whereas crucifer infecting Olpidium isolates did not transmit these viruses. They also showed those isolates from 
lettuce tended to efficiently transmit MLBVV, but not TStV and those from tobacco efficiently transmitted TStV, but not MLBVV. As some of their lettuce isolates had $100 \%$ ITS homology with one of the tobacco isolates, this suggests there is no meaningful relationship between ITS sequences and virus-vectoring specificities. Further research is needed on the virus-vectoring specificities of some Olpidium isolates in order to determine the commercial importance of discrimination between host-specific groups, for example it is not known whether the O. brassicae isolate from carrot which infects lettuce, is capable of transmitting lettuce viruses.

ITS and 5.8S sequence comparisons have highlighted the fact that lettuce-infecting, brassica-infecting and a cucurbit-infecting isolates of $O$. brassicae are different from each other and phylogenetic analysis has shown that there are distinct genetic branches within the brassica- and lettuce-infecting groupings, but also that $O$. brassicae isolates are more closely related to each other, than to any other species. It has also revealed geographic groupings and provided an insight in to spread and geographic isolation of Olpidium.

\section{Acknowledgments}

Isolates were gratefully received from J. Bambridge, R. Campbell, G. Collier, C. Hiruki, the late P. Roggero, P. Sastre Castro, H. Van den Heuvel, F. Van der Wilk, J. Vetten, J. Schutt and J. Webster. We thank Judith Bambridge for technical assistance in cultivating the Olpidium isolates, Rachel Edwards for sequencing, Carol Jenner for preparing the PRT2 isolate for DNA sequencing, Christian Obermeier for help with 
the phylogenetic analysis and Dez Barbara for critical review of this manuscript. This work was funded by the European Commission funded project QLRT-1999-1471, project co-ordinator: R.A.A. van der Vlugt.

\section{REFERENCES}

Altschul SF, Madden TL, Schäffer AA, Zhang J, Zhang Z, Mille W, Lipman DJ, 1997. Gapped BLAST and PSI-BLAST: a new generation of protein database search programs. Nucleic Acids Research 25: 3389-3402.

Balardin RS, Smith JJ, Kelly JD, 1999. Ribosomal DNA polymorphism in Colletotrichum lindemuthianum. Mycological Research 103: 841-848.

Campbell RN, 1985. Longevity of Olpidium brassicae in air-dry soil and the persistence of the lettuce big-vein agent. Canadian Journal of Botany 63: 2288-2289.

Campbell RN, 1996. Fungal transmission of plant viruses. Annual Review of Phytopathology 34: 87-108.

Campbell RN, Sim ST, 1994. Host specificity and nomenclature of Olpidium bornovanus (= Olpidium radicale) and comparisons to Olpidium brassicae. Canadian Journal of Botany 72: 1136-1143. 
Cooke DEL, Duncan JM, 1997. Phylogenetic analysis of Phytophthora species based on ITS1 and ITS2 sequences of the ribosomal RNA gene repeat. Mycological Research 103: 799-804.

Duggal A, Dumas MT, Jeng RS, Hubbes M, 1997. Ribosomal variation in six species of Fusarium. Mycopathology 140: 35-49.

Felsenstein J, 1995. PHYLIP (phylogeny inference package) version 3.75c. Distributed by Department of Genetics, University of Washington, Seattle, WA.

Garrett RG, Tomlinson JA, 1967. Isolate differences in Olpidium brassicae. Transactions of the British Mycological Society 50: 429-435.

Herrera-Vásquez JA, Cebrián MC, Alfaro-Fernández A, Córdoba-Sellés MD, Jordá C, 2009. Multiplex PCR assay for the simultaneous detection and differentiation of Olpidium bornovanus, O. brassicae O. virulentus. Mycological Research 113: 602610.

Huijberts N, Blystad D-R, Bos L, 1990. Lettuce big-vein virus: mechanical transmission and relationships to tobacco stunt virus. Annals of Applied Biology 116: 463-475.

James TY et al. 2006. Reconstructing the early evolution of fungi using a six-gene phylogeny. Nature 443: 818-822. 
Jung T, Nechwatal J, Cooke DEL, Hartmann G, Blaschke M, Osswald WF, Duncan JM, Delatour C, 2003. Phytophthora pseudosyringae sp nov., a new species causing root and collar rot of deciduous tree species in Europe. Mycological Research 107: 772-789.

Kuwata S, Kubo S, Yamashita S, Doi Y, 1983. Rod-shaped particles, a probable entity of lettuce big vein virus. Annals of Phytopathological Society of Japan 49: 246-251.

Lange L, Insunza V, 1977. Root-inhabiting Olpidium species: the O. radicale complex. Transactions of the British Mycological Society 69: 377-384.

Lot H, Campbell RN, Souche S, Milne RG, Roggero P, 2002. Transmission by Olpidium brassicae of Mirafiori lettuce virus and Lettuce big-vein virus, and their roles in lettuce big-vein etiology. Phytopathology 92: 288-293.

Muthumeenakshi S, Goldstein AL, Stewart A, Whipps JM, 2001. Molecular studies on intraspecific diversity and phylogenetic position of Coniothyrium minitans. Mycological Research 105: 1065-1074.

Olsen GJ, Matsuda H, Hagstrom R, Overbeek R, 1994. fastDNAML: A tool for construction of phylogenetic trees of DNA sequences using maximum likelihood. Computer Applications in the Biosciences 10: 41-48 
Perrière G, Gouy M, 1996. WWW-Query: An on-line retrieval system for biological sequence banks. Biochimie 78: 364-369

Ryder EJ, 1980. Studies on sources and nature of big vein resistance in lettuce and progress in breeding resistant cultivars. In Proceedings of Eucarpia Meeting on Leafy Vegetables (Maxon Smith JW, Langton FA, eds), 78-85. Glasshouse Crop Research Institute, Littlehampton, UK.

Sahtiyanci S, 1962. Studien über einige wurzelparasitäre Olpidiaceen. Archives of Microbiology 41: 187-228.

Sasaya T, Koganezawa H, 2006. Molecular analysis and virus transmission tests place Olpidium virulentus, a vector of Mirafiori lettuce big-vein virus and tobacco stunt virus, as a distinct species rather than a strain of Olpidium brassicae. Journal of General Plant Pathology 72: 20-25.

Teakle DS, Gold AH, 1964. Prolonging the motility and virus transmitting ability of Olpidium zoospores with chemicals. Phytopathology 54: 29-32.

Thompson JD, Gibson TJ, Plewniak F, Jeanmougin F, Higgins DG, 1997. The ClustalX windows interface: flexible strategies for multiple sequence alignment aided by quality analysis tools. Nucleic Acids Research 24: 4876-4882. 
Tomlinson JA, Thomas BJ, 1986. Studies on melon necrotic spot virus disease of cucumber and on the control of the fungus vector (Olpidium radicale). Annals of Applied Biology 108: 71-80.

Walsh JA, 1992. Catching up with big vein. Grower December 3, 11-15.

Walsh JA, 1994. Effects of some biotic and abiotic factors on symptom expression of lettuce big-vein virus in lettuce (Lactuca sativa). Journal of Horticultural Science 69: 21-28.

Ward E, Adams MJ, 1998. Analysis of ribosomal DNA polymyxa species and related fungi and the development of genus- and species- specific PCR primers. Mycological Research 102: 965-974.

White TJ, Bruns T, Lee S, Taylor J, 1990. Amplification and direct sequencing of fungal ribosomal RNA genes for phylogenetics. In PCR Protocols: A Guide to Methods and Applications (Innis MA, Gelfand DH, Snisky JJ, White TJ, eds), 315322. Academic Press, San Diego.

Zhang Z, Schwartz S, Wagner L, Miller W, (2000). A greedy algorithm for aligning DNA sequences. Journal of Computational Biology 7: 203-214. 